\title{
Regenerated cellulose scaffolds: Preparation, characterization and toxicological evaluation
}

\author{
Adalberto M. de Araújo Júnior ${ }^{\mathrm{a}, 1}$, Guilherme Braido ${ }^{\mathrm{b}, 1}$, Sybele Saska ${ }^{\mathrm{a}}$, \\ Hernane S. Barud ${ }^{\mathrm{a}, \mathrm{c}}$, Leonardo P. Franchi ${ }^{\mathrm{d}}$, Rosana M.N. Assunção ${ }^{\mathrm{e}}$, \\ Raquel M. Scarel-Caminaga ${ }^{\mathrm{b}}$, Ticiana S.O. Capote ${ }^{\mathrm{b}}$, Younès Messaddeq ${ }^{\mathrm{a}}$, \\ Sidney J.L. Ribeiro ${ }^{\mathrm{a}, *}$ \\ a Institute of Chemistry, São Paulo State University, UNESP, PO Box 355, Araraquara, SP 14800-970, Brazil \\ b Dental School at Araraquara, São Paulo State University, UNESP, Rua Humaitá, 1680, 14803-901 Araraquara, SP, Brazil \\ ${ }^{\mathrm{c}}$ Laboratório de Química Medicinal e Medinica Regenerativa (QUIMMERA), Centro Universitário de Araraquara (UNIARA), Araraquara, SP, Brazil \\ d Ribeirão Preto Medical School, University of São Paulo, USP, Av. Bandeirantes, 3900 Ribeirão Preto, SP, Brazil \\ e Faculdade de Ciências Integradas do Pontal, Universidade Federal de Uberlândia, Campus do Pontal, Rua Vinte, 1600, 38304-402 Ituiutaba, MG, Brazil
}

\section{A R T I C L E I N F O}

\section{Article history:}

Received 21 May 2015

Received in revised form 26 August 2015

Accepted 21 September 2015

Available online 25 September 2015

\section{Keywords:}

Regenerated cellulose

Scaffold

Tissue repair

Cytotoxicity

Genotoxicity

Mutagenicity

\begin{abstract}
A B S T R A C T
Regenerated cellulose scaffolds (RCS) may be used as alloplastic materials for tissue repair. In this work the RCS were obtained by viscose process and characterized by scanning electron microscopy (SEM), wide angle X-ray diffraction (WAXD), Fourier transform infrared spectroscopy (FTIR) and thermogravimetry analysis (TG). In vitro enzymatic degradation assay and toxicological assays were also evaluated. The physicochemical characterizations revealed the formation of a porous material with distinct thermal profile and crystallinity compared to pristine cellulose pulp. Enzymatic degradation assay revealed that lysozyme showed a mildest catalytic action when compared to cellulase, Tricoderma reesei ( Tr). Nevertheless, both enzymes were efficient for degrading the RCS. RCS did not show cytotoxicity, mutagenic or genotoxic effects. The systematically characterization of this work suggests that RCS presented distinct features that make it a viable material for future studies related to the development of scaffolds for biological applications.
\end{abstract}

(c) 2015 Elsevier Ltd. All rights reserved.

\section{Introduction}

Cellulose, the most abundant natural polymer on Earth (Klemm, Heublein, Fink, \& Bohn, 2005), is a linear homopolysaccharide that represents the largest component of plant biomass. It consists of units of $\beta$-D-glucopyranose ( $\beta$-glucose) linked by glycosidic type $\beta-(1 \rightarrow 4)$.

Industrially cellulose is widely used in paper production as emulsifying, dispersing agent, gelling agent, among other functions, with interesting features such as biodegradability,

\footnotetext{
* Corresponding author.

E-mail addresses: adalberto_araujojunior@outlook.com (A.M. de Araújo Júnior), guilhermevvbraido@foar.unesp.br

(G. Braido), sysaska@gmail.com (S. Saska), hernane.barud@gmail.com (H.S. Barud), leonardofranchi@yahoo.com.br (L.P.Franchi), rosanassuncao@gmail.com (R.M.N. Assunção), raquel@foar.unesp.br (R.M. Scarel-Caminaga),

ticiana@foar.unesp.br (T.S.O.Capote),younes.messaddeq@copl.ulaval.ca (Y. Messaddeq), sidney@iq.unesp.br (S.J.L. Ribeiro).

1 These authors contributed equally to this paper.
}

biocompatibility, no toxicity and no allergenicity (Czaja, Krystynowicz, Bielecki, \& Brown, 2006). The physicochemical properties of cellulose have attracted great interest in the production of new materials in various areas, such as electronics (LCD screens), energy (fuel cell membranes), communications (diaphragms for microphones and stereo headphones) and medicine (temporary artificial skin for burns and ulcers). In recent years, there is an increase in interest for using cellulose for medical applications, especially in exploring new porous biomaterials, which might be used for tissue engineering (Hench \& Polak, 2002).

An ideal biomaterial must provide variety of shapes and sizes, and also be tough enough to be used in locations where there is impact load. Moreover, it must also be biocompatible, absorbable and replaced by new tissue formation, in case of application in tissue engineering (Karageorgiou \& Kaplan, 2005; Spector, 2008). Currently, natural polymers are important alternatives in obtaining scaffolds for tissue repair (Liu \& Ma, 2004).

Concerning regenerated cellulose, it may be obtained by the well-known viscose rayon process. In short, cellulose pulp is treated with sodium hydroxide and carbon disulfide solutions, leading to 
cellulose xanthate. Regeneration of cellulose occurs by acid hydrolysis of xanthates groups using sulfuric acid solution. In this step, the xanthate groups are released from the main chain of cellulose and the cellulose is regenerated (Cross, E.J. Bevan, \& Beadle, 1893; Cross, E.T. Bevan, \& Beadle, 1893).

The applicability of regenerated cellulose in tissue repair is being evaluated. Martson, Viljanto, Hurme, and Saukko (1998) evaluated the biocompatibility of scaffolds based on regenerated cellulose for bone repair in rats. They showed that regenerated cellulose was a compatible and osteoconductive matrix, promoting new bone formation. Cullen et al. (2002) described a new wound treatment using oxidized regenerated cellulose (ORC) and collagen (ORC/collagen). The ORC/collagen composite was able to inactivate potentially harmful factors (proteases, oxygen free radicals and excess metal ions) presented in chronic wound fluid, and therefore promote healing. Additionally, the effectiveness of pharyngeal mucosal healing using ORC was also reported (Liu et al., 2012). Nevertheless, further studies are necessary to establish a comparison among different biomaterials and to evaluate the application of regenerated cellulose scaffolds in clinical practice. Considering that the human body does not express naturally the cellulase enzymes able to degrade cellulose (Hu \& Catchmark, 2011a) and in order to obtain in vivo resorption of the cellulose, this study evaluated the in vitro enzymatic degradation for regenerated cellulose scaffolds using two different enzymes, Trichomona reesei cellulase and lysozyme.

Once a material undergoes chemical modification, it is necessary to investigate whether these chemical changes lead to cytotoxic effects. For this reason, in this study the modified cellulose was investigated in respect to their cytotoxic, genotoxic and mutagenic effects. These studies are important to evaluate the behavior of the regenerated cellulose for future in vivo applications.

Therefore, this study aimed to prepare regenerated cellulose scaffold, systematically characterize it, and evaluate its enzymatic degradation as well. In addition, the potential cytotoxic, genotoxic and mutagenic effects of these materials were evaluated.

\section{Experimental}

\subsection{Preparation of regenerated cellulose scaffolds}

Pristine cellulose pulp (CP) and pristine regenerated cellulose scaffold (RCS), prepared by the viscose process, were supplied by Coopercell Ind. de Papel Celofane (São Paulo, Brazil). Cellulose was firstly immersed in $18 \%(\mathrm{w} / \mathrm{v}) \mathrm{NaOH}$ solution at room temperature; subsequently the alkali cellulose was reacted with $\mathrm{CS}_{2}$ solution at $30^{\circ} \mathrm{C}$ for 90 min leading to cellulose xanthate. $\mathrm{H}_{2} \mathrm{SO}_{4}$ solution was added regenerating cellulose. The formation of regenerated cellulose scaffold with controlled pore size was possible using porogenic agent, $\mathrm{Na}_{2} \mathrm{SO}_{4}$, with different grain sizes around $100-200 \mu \mathrm{m}$.

\subsection{SEM characterization of the samples}

Scanning electron microscopy images were obtained from a TOPCON 600. Samples were coated with a $20 \mathrm{~nm}$ thick gold layer.

\subsection{WAXD characterization}

WAXD patterns were obtained in a Siemens Kristalloflex diffractometer using nickel filtered $\mathrm{Cu} \mathrm{K} \alpha$ radiation, step pass of $0.02^{\circ}$ and a step time of $3 \mathrm{~s}$, from 4 to $70^{\circ}$ ( $2 \theta$ angle). The separation of the crystalline peaks and the amorphous halo was performed by deconvolution using a Pseudo-Voigt function. $W_{L}$ and $W_{G}$ are widths at half height for the Gaussian and the Lorentz components of the equation, $A$ is the area and $m_{u}$ is the sum factor.

$$
\begin{aligned}
y= & y_{0}+A\left[m_{u} \frac{2 w_{L}}{\pi 4\left(x-x_{c}\right)^{2}+w_{L}^{2}}\right. \\
& \left.+\left(1-m_{u}\right) \frac{\sqrt{4 \ln 2}}{\sqrt{\pi w_{G}}}\left(-\frac{4 \ln 2}{w_{G}^{2}}\right)\left(x-x_{c}\right)^{2}\right]
\end{aligned}
$$

The crystallinity index ( $\mathrm{CrI}$ ) can be calculated from Eq. (2). Where $A_{c}$ and $A_{a}$ are areas of the crystalline peaks and amorphous halo, respectively.

$\% C=\frac{A_{c}}{A_{c}+A_{a}} \times 100$.

\subsection{FTIR characterization}

FTIR spectra were obtained with dried powdered samples on a PerkinElmer Spectrum 1000 Fourier Transform Infrared Spectrophotometer. Pellets were prepared from mixtures of the samples and $\operatorname{KBr}(1: 100$ in weight). Twenty-eight scans were accumulated at a resolution of $4 \mathrm{~cm}^{-1}$.

\subsection{Thermal behavior}

TG curves were obtained with a SDT equipment from TA Instruments. The conditions used in the experiments were the following: nitrogen atmosphere at a flow rate of $50 \mathrm{~mL} \mathrm{~min}^{-1}$, heating rate of $10^{\circ} \mathrm{C} \mathrm{min}^{-1}$ from $10^{\circ}$ to $600^{\circ} \mathrm{C}$ and alumina pans.

\subsection{Enzymatic degradation}

In vitro enzymatic degradation was evaluated using two enzymes, Trichoderma reesei cellulase (Sigma ${ }^{\circledR}$ ) and Lysozyme $\left(\right.$ Sigma $\left.{ }^{\circledR}\right)$. Two different concentrations of these enzymes $\left(0.5 \mathrm{U} \mathrm{mL}^{-1}\right.$ and $\left.1 \mathrm{U} \mathrm{mL}^{-1}\right)$ were used and solutions were prepared in $\mathrm{Na}_{2} \mathrm{HPO}_{4}$-Citric acid buffer solution ( $\mathrm{pH}$ 5.0), containing $0.1 \mathrm{~mol} \mathrm{~L}^{-1}$ citric acid and $0.2 \mathrm{~mol} \mathrm{~L}^{-1}$ sodium hydrogen phosphate in a ratio $1: 1$. The lyophilized RCS samples were cut $1 \mathrm{~cm}^{3}$ in size, and $1 \mathrm{~mL}$ of each respective enzymatic solution was dripped over the samples; then, these samples were lyophilized for $24 \mathrm{~h}$. Degradation of the samples was performed in simulated body fluid (SBF) solution (Kokubo, Kushitani, Sakka, Kitsugi, \& Yamamuro, 1990), $\mathrm{pH} 7.2$ at $37^{\circ} \mathrm{C}$ for 56 days. Samples were placed into 24-wells plate for cell culture (Corning ${ }^{\circledR}$ ) and $2.5 \mathrm{~mL}$ of SBF solution was added to each well. Control samples, without enzyme, were also prepared for comparison. The degree of degradation was evaluated by weighing method using semi-analytical balance at $3,7,14$, $21,28,42$ and 56 days. After each analysis period, the samples were removed from the SBF solution and lyophilized for $48 \mathrm{~h}$. The lyophilized samples were weighed to calculate the percentage of mass loss. The experiment was performed in triplicate.

\subsection{Cell culture experiments}

Eluates of RCS were made according to ISO 10993-12:2008, considering the weight $(0.2 \mathrm{~g} \mathrm{~mL})$. The RCS were immersed in $1: 1$ Ham-F10 + D-MEM medium (Sigma ${ }^{\circledR}$, St. Louis, MO) without fetal bovine serum (FBS) at $37^{\circ} \mathrm{C}$ for $72 \mathrm{~h}$, shaking at $133 \mathrm{rpm}$ in an incubator (New Brunswick Scientific - Excella E24 Incubator Shaker Series). Four different concentrations were used: RCS100\% (100\% eluate), RCS75\% (75\% eluate + 25\% 1:1 Ham-F10 + D-MEM medium), RCS 50\% (50\% eluate +50\% 1:1 Ham-F10 + D-MEM medium) and RCS25\% (25\% eluate + 75\% 1:1 Ham-F10 + D-MEM medium). 


\subsubsection{CHO-K1 cell culture}

CHO-K1 cells were cultured in 1:1 Ham-F10 + D-MEM medium $\left(\right.$ Sigma $^{\circledR}$, St. Louis, MO) supplemented with $10 \%$ FBS (Cultilab, Campinas, Brazil) and antibiotics $\left[\left(0.06 \mathrm{~g} \mathrm{~L}^{-1}\right.\right.$ penicillin $\left(\operatorname{Sigma}{ }^{\circledR}\right)$, $0.10 \mathrm{~g} \mathrm{~L}^{-1}$ streptomycin $\left(\right.$ Sigma $\left.^{\circledR}\right), 1 \%$ kanamycin (Gibco, Carlsbad, CA) and $1 \%$ ciprofloxacin (Hifloxan ${ }^{\circledR}$, Halexistar)] in $25 \mathrm{~cm}^{2}$ culture flasks at $37^{\circ} \mathrm{C}, 5 \% \mathrm{CO}_{2}$. Cells were used between the third and eighth passages.

\subsubsection{Cytotoxicity tests}

2.7.2.1. XTT assay. After 24 h of seeding, CHO-K1 cells $\left(2 \times 10^{4}\right.$ cells seeded) were treated with RCS100\%, RCS75\%, RCS50\% and RCS25\% eluates (in duplicate) for $24 \mathrm{~h}$ in 24 -well plates. Each well containing eluate was supplemented with $10 \%$ FBS. Negative controls (NC) were wells with culture medium supplemented with $10 \%$ FBS in the absence of any eluate (untreated controls), while positive controls (PC), well containing CHO-K1 cells, were treated with doxorubicin ( $3 \mu \mathrm{g} \mathrm{mL} \mathrm{m}^{-1}$ ) for $24 \mathrm{~h}$ (all treatments were carried out in duplicate). After treatment, the cultures were washed with PBS solution and fresh medium was added. After $24 \mathrm{~h}$ of incubation, the cultures were washed with PBS solution and immediately $500 \mu \mathrm{L}$ of DMEM without phenol red were added, followed by the addition of $60 \mu \mathrm{L}$ of the XTT/electron solution (50:1) (Cell Proliferation Kit II - Roche Applied Science). After $3 \mathrm{~h}$ reaction, the supernatant was transferred to a 96-well culture plate, and the absorbance was measured by a Microplate Reader (VersaMax, Molecular Devices, Sunnyvale, CA) at 492 and $690 \mathrm{~nm}$. The absorbance is directly proportional to the number of viable cells in each treatment after $24 \mathrm{~h}$ of exposure. Three independent experiments were conducted.

2.7.2.2. Clonogenic assay. After $24 \mathrm{~h}$ of seeding, CHO-K1 cells ( $5 \times 10^{4}$ cells seeded) were exposed for $24 \mathrm{~h}$ to RCS100\%, RCS75\%, RCS50\% and RCS25\% eluates (in duplicate) for $24 \mathrm{~h}$ in 24 -well plates. Each eluate well was supplemented with $10 \%$ FBS. Negative controls (NC) were wells with culture medium supplemented with $10 \%$ FBS in the absence of any eluate, while positive controls (PC), well containing $\mathrm{CHO}-\mathrm{K} 1$ cells, were treated with hydrogen peroxide ( $80 \mu \mathrm{mol} \mathrm{L}^{-1}$ for $10 \mathrm{~min}$ ) (all treatments were carried out in duplicate). After exposure, the cultures were washed with PBS solution and fresh medium was added. Exponentially growing cells were seeded after treatment at a number of 150 cells per $25 \mathrm{~cm}^{2}$ flasks, in duplicate for each treatment. The flasks were incubated at $37^{\circ} \mathrm{C}$, $5 \% \mathrm{CO}_{2}$, for 7 days without medium exchange. The colonies that formed were fixed with methanol:acetic acid:water $(1: 1: 8, \mathrm{v} / \mathrm{v} / \mathrm{v})$ and stained with $5 \%$ Giemsa. The colonies were counted, and the cell surviving fraction was calculated as percent colonies in treated flasks relative to untreated controls (NC). Three independent experiments were conducted.

\subsubsection{Genotoxicity and mutagenicity assays}

2.7.3.1. Comet assay. The alkaline version of the comet assay was used according to the method described by Singh, McCoy, Tice, and Schneider (1988). CHO-K1 cells were seeded $\left(5 \times 10^{4}\right.$ cells seeded $)$ and after $24 \mathrm{~h}$ they were exposed to RCS $100 \%$, RCS75\%, RCS50\% and RCS25\% eluates (in duplicate) for $24 \mathrm{~h}$ (in duplicate) in 24well plates. Each eluate well was supplemented with 10\% FBS. Negative controls (NC) were wells with culture medium supplemented with $10 \%$ FBS in the absence of any eluate, while positive controls (PC) were treated with hydrogen peroxide $\left(80 \mu \mathrm{mol} \mathrm{L}^{-1}\right.$ for $10 \mathrm{~min}$ ) (all treatments were carried out in duplicate). After exposure, the cultures were washed with PBS solution and harvested with trypsin. Five hundred microliters of cells in suspension were obtained, kept on ice and protected from light. After centrifugation, the pellet was re-suspended in $200 \mu \mathrm{L}$ of $0.5 \%(\mathrm{w} / \mathrm{v})$ low melting point agarose and the mixture was spread onto two microscope slides (Knittel, Germany) pre-coated with $1.5 \%$ (w/v) normal melting point agarose (Gibco). Coverslips were placed over the gel. When the gels had solidified, the coverslips were gently removed and the slides were immersed in cold $\left(4^{\circ} \mathrm{C}\right)$ lysis solution $(1 \% \mathrm{Tri}-$ ton X-100, 10\% DMSO, $2.5 \mathrm{mmol} \mathrm{L}^{-1} \mathrm{NaCl}, 100 \mathrm{mmol} \mathrm{L}^{-1} \mathrm{Na}_{2}$ EDTA, $100 \mathrm{mmol} \mathrm{L}^{-1}$ Tris, $\mathrm{pH} \mathrm{10)} \mathrm{for} 24 \mathrm{~h}$. Immediately after this step, slides were placed in a horizontal electrophoresis unit containing freshly prepared electrophoresis buffer $\left(1 \mathrm{mmol} \mathrm{L}^{-1} \mathrm{Na}_{2}\right.$ EDTA, $300 \mathrm{mmol} \mathrm{L}^{-1} \mathrm{NaOH}, \mathrm{pH}>13$ ). The DNA was allowed to unwind for $20 \mathrm{~min}$ and subsequently electrophoresis was performed at $25 \mathrm{~V}$, $300 \mathrm{~mA}$ for $20 \mathrm{~min}$. Afterward, the slides were gently immersed in neutralization buffer $\left(0.4 \mathrm{~mol} \mathrm{~L}^{-1}\right.$ Tris- $\left.\mathrm{HCl}, \mathrm{pH} 7.5\right)$ for $15 \mathrm{~min}$ and then fixed with ethanol. All the steps of comet assay were conducted under subdued light. Three independent experiments were conducted.

DNA damage was determined in a blind test in 100 nucleoids per slide. Duplicate slides were prepared, stained with ethidium bromide, and screened with a fluorescent microscope (ZEISS ${ }^{\circledR}$, Jena, Thuringia, DEU) equipped with an excitation filter of $515-560 \mathrm{~nm}$, a barrier filter of $590 \mathrm{~nm}$ and a $40 \times$ objective. The level of DNA damage was assessed by an image analysis system (TriTek CometScore ${ }^{\circledR}$ $1.5,2006$, Sumerduck, VA, USA), and the DNA percentage in the tail and Tail Moment were obtained for each treatment. A visual score was also used to compute DNA damage from comets. Five classes were used, from 0 (no tail) to 4 (almost all DNA in tail) (Azqueta et al., 2011; Collins, 2004). The DNA Damage Index (DDI) was calculated using the following formula (Teixeira et al., 2009):

DDI $=\frac{0(n \text { level } 0)+1(n \text { level } 1)+2(n \text { level } 2)+3(n \text { level } 3)+4(n \text { level } 4)}{.}$ total of comets analyzed

2.7.3.2. Cytokinesis-blocked micronucleus (CBMN) assay for mutagenicity evaluation. CBMN assay was performed according to Fenech (2000) with minor modifications. CHO-K1 cells ( $37 \times 10^{4}$ cells/culture flask) were seeded in $25 \mathrm{~cm}^{2}$ culture flasks at $37{ }^{\circ} \mathrm{C}, 5 \% \mathrm{CO}_{2}$. After $24 \mathrm{~h}$ of seeding, cells were exposed for $24 \mathrm{~h}$ to RCS100\%, RCS75\%, RCS50\% and RCS25\% eluates (in duplicate). Each eluate culture flask was supplemented with $10 \%$ FBS. Negative controls (NC) were culture flasks with culture medium supplemented with $10 \%$ FBS in the absence of any eluate (untreated controls), while positive controls (PC) were treated with doxorubicin $\left(0.15 \mu \mathrm{g} \mathrm{mL}^{-1}\right)$ for $4 \mathrm{~h}$. Cytochalasin-B (CytB) was added to the $\mathrm{CHO}-\mathrm{K} 1$ cultures at a final concentration of $5 \mu \mathrm{g} \mathrm{mL}^{-1}$ and left for $20 \mathrm{~h}$. After treatments, the cultures were washed with PBS solution, trypsinized and centrifuged for $5 \mathrm{~min}$ at $1500 \mathrm{rpm}$. The pellet was then resuspended in cold hypotonic solution $(0.3 \%$ $\mathrm{KCl}, \mathrm{w} / \mathrm{v}$ ) for $3 \mathrm{~min}$. Cells were fixed twice with methanol:glacial acetic acid (3:1, v/v) and with four drops of formaldehyde, and then homogenized carefully with a Pasteur pipette. The cell suspensions were dripped on a slide with a film of distilled water at $4{ }^{\circ} \mathrm{C}$. The slides were stained with $5 \%$ Giemsa solution diluted in phosphate buffer $\left(\mathrm{Na}_{2} \mathrm{HPO}_{4} 0.06 \mathrm{~mol} \mathrm{~L}^{-1}, \mathrm{KH}_{2} \mathrm{PO}_{4} 0.06 \mathrm{~mol} \mathrm{~L}^{-1}-\mathrm{pH} 6.8\right)$ for $7 \mathrm{~min}$, washed with distilled water, air dried and examined by light microscopy ( $400 \times$ magnification). Three independent experiments were conducted.

Five hundred (500) viable cells were scored to determine the frequency of cells with $1,2,3$ or 4 nuclei and calculated the nuclear division index (NDI) using the formula: $[\mathrm{NDI}=\mathrm{M} 1+2(\mathrm{M} 2)+3(\mathrm{M} 3)+4(\mathrm{M} 4) / \mathrm{N}]$, where $\mathrm{M} 1-\mathrm{M} 4$ represents the number of cells with 1-4 nuclei, respectively, and $\mathrm{N}$ is the total number of viable cells scored (Eastmond \& Tucker, 1989; Fenech, 2000). The frequency of binucleated cells with micronuclei (MNBCF) and the total frequency of micronuclei (MF) were scored in 1000 binucleated cells. The criteria used for identifying micronuclei were based on Fenech (2000). 


\subsubsection{Statistical analysis}

The results were expressed as mean and standard error. Oneway analysis of variance (ANOVA) followed by Tukey's test was applied to the data. Data from treated groups were compared to the negative control using Dunnett's test. BioEstat statistical package v. 5 was used (UFPA, Belém, Brazil) to perform the tests. Differences were considered statistically significant when $p<0.05$.

\section{Results and discussion}

\section{1. $C P$ and RCS characterization}

CP and RCS showed different morphologies due to the modification of hydrogen bond patterns and crystalline structure during regeneration process. Porous samples can be easily produced by adding a pore forming material (sodium sulfate salt) in the cellulose solution.

The original cellulose $(\mathrm{CP})$ and the porous regenerated cellulose (RCS) are presented in photographs of Fig. 1a and b, respectively. The morphology of the samples was evaluated by using scanning electron microscopy (SEM), the micrographs are shown in Fig. 1c-h. A fibrous structure is observed for $\mathrm{CP}$ (Fig. 1c and d) and a porous one for RCP samples (Fig. 1e-h). The last one showed different profile of pore distribution, which may be controlled by proper choice of pore forming agents. The porous structure of RCS was produced by adding sodium sulfate crystals in the viscose slurry during the regeneration process. Crystals may be easily removed in hot water. Pores showed different sizes and shapes, an important aspect considering the production of scaffolds.

The ability to control the pore size is a decisive factor in the use of some material in the manufacture of scaffolds in tissue regeneration (Rambo et al., 2008). Fig. 1f and h showed the morphological characteristics of the porous RCS sample. The optimal pore size depends on the tissue to be repaired. For soft tissues, pores in the $20-120 \mu \mathrm{m}$ range allow fibroblast migration and other cells, and avoid wound contraction allowing wound healing. In the case of scaffolds for bone regeneration, the optimal pore size is in the 100-300 $\mu \mathrm{m}$ range (Karageorgiou \& Kaplan, 2005). RCS displays two types of porosity; the pores formed by porogenic agents with diameters between 100 and $1000 \mu \mathrm{m}$ and pores formed during coagulation and regeneration in the viscose process (in the absence of pore-forming agent) inside cellulosic matrix (diameter: 1-10 $\mu \mathrm{m}$ ) (Martson, Viljanto, Hurme, Laippala, \& Saukko, 1999).

Fig. 2 shows the X-ray diffractions patterns obtained for CP and RCS. In fig. 2(a) 3 peaks are observed at $2 \theta=14.9^{\circ}, 16.3^{\circ}$ and $22.7^{\circ}$ for $\left(\begin{array}{ll}1 & 10\end{array}\right)$ and $(200)$ planes characteristic of cellulose I structure. For regenerated cellulose (Fig. 2(b)) a drastic change is observed. A peak is observed at $2 \theta=12.2^{\circ}$ and a broad halo centered at $22^{\circ}$ that has the contribution of two diffraction peaks at $2 \theta=19.6^{\circ}$ and $22.3^{\circ}$, assigned to (110) and (200) planes of the cellulose II structure.

Crystallinity is lower for RCS as concluded from the Crystallinity Index that was obtained by measuring the ratio of crystalline peaks area and the total area (Eq. (2)). The deconvolution of crystalline peaks and amorphous halo was performed by using Pseudo-Voigt 2 function. Fig. 2a and b showed the XRD patterns of CP and RCS and fitting curves obtained by deconvolution. The Crystallinity Index obtained for the CP and RCS was $73 \%$ and $44 \%$, respectively. This result is expected due to the process of regeneration of cellulose. The decrease in the crystallinity of the cellulose increases its water absorption and biodegradability. With decreasing crystallinity cellulose fibers get more disorganized and hence more susceptible to degradation processes. Therefore, amorphous regions are more susceptible to enzymatic degradation (Beguin \& Aubert, 1994). This is one aspect which makes regenerated cellulose a material suitable for design of tissue engineering scaffolds once the biodegradability

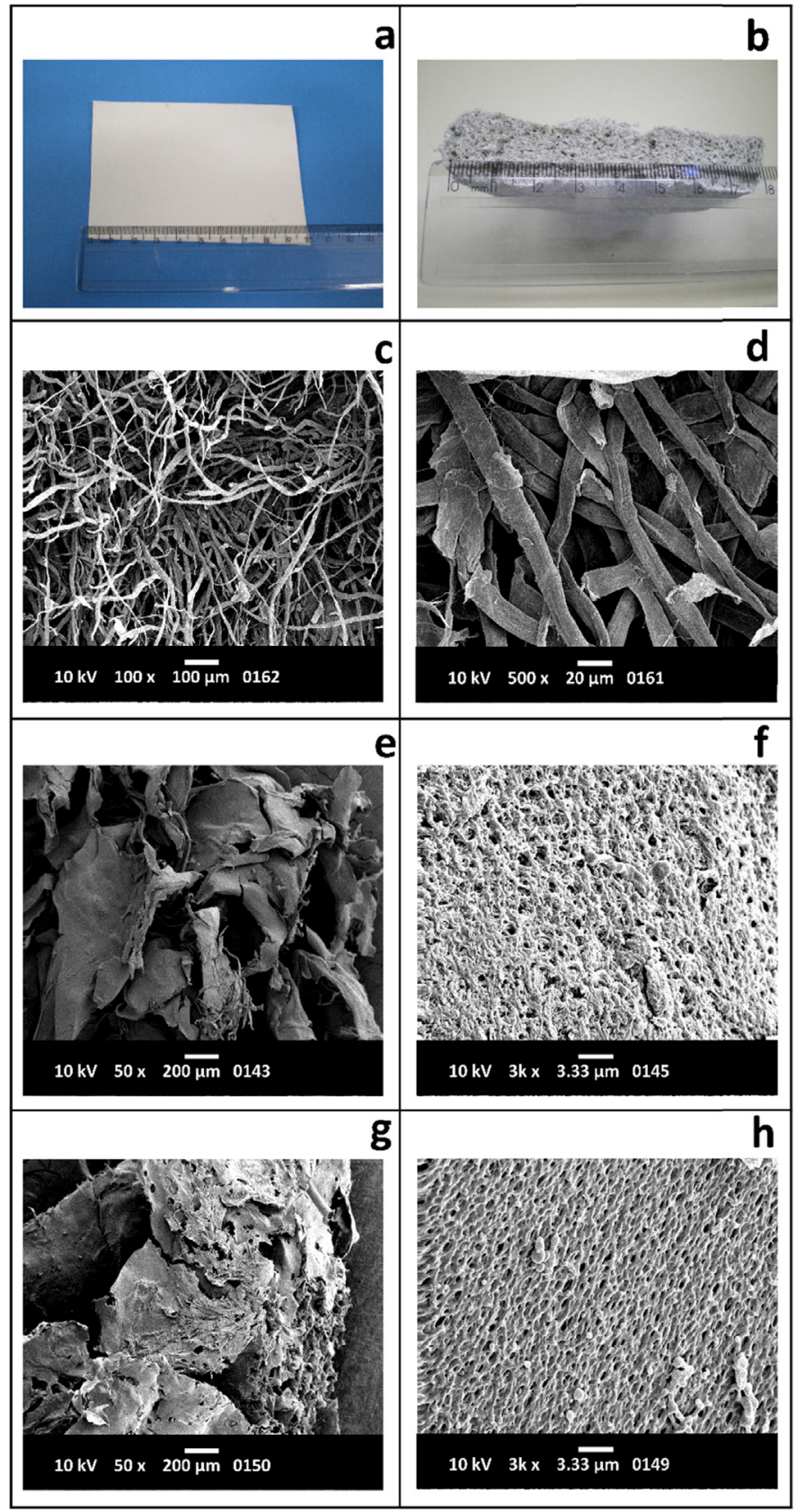

Fig. 1. (a) Cellulose pulp sheet (CP) photo; (b) porous regenerated cellulose (RCS) photo; (c and d) SEM micrographs of cellulose pulp (CP) fibers; (e and h) SEM micrographs of porous regenerated cellulose (RCS) samples with different porosity.

is one aspect needed to application of this material. Importantly, the rate of biodegradation process of the RCS should be similar to the biological process rate. However, to avoid resorption of the scaffold device, low rate of degradation is always preferable (Sannino, Demitri, \& Madaghiele, 2009).

Cellulose structure could be also accessed by FTIR spectroscopy. Spectra are showed in supplementary material and lead to the conclusion that $\mathrm{CP}$ is constituted of cellulose I while the RCS displays only the structure of cellulose II corroborating DRX results.

Fig. 3 shows TG curves. Two stages of mass loss are observed for CP (Fig. 3a). The first stage, between 25 and $80^{\circ} \mathrm{C}$, is related to desorption of water from the polysaccharide structure. The second stage, between 250 and $330^{\circ} \mathrm{C}$, is related to cellulose degradation (depolymerization, dehydration and glycoside units decomposition) followed by the formation of carbon residues 


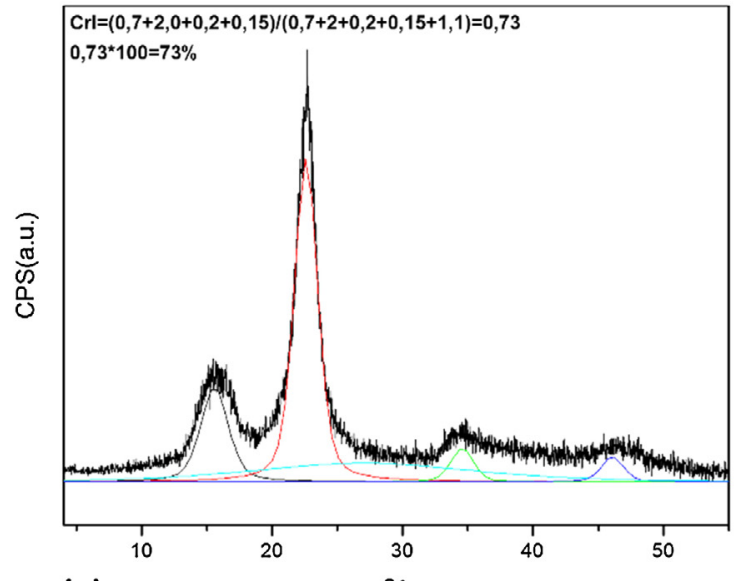

(a)

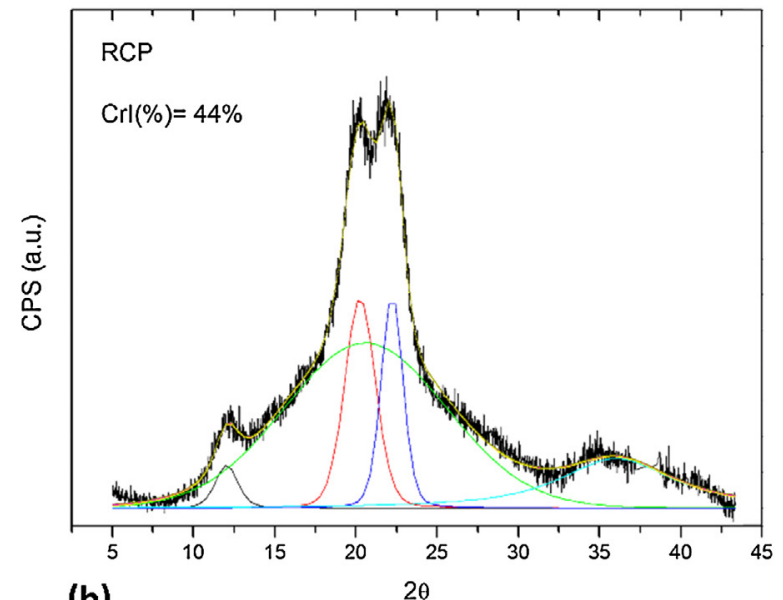

(b)

Fig. 2. X-ray diffraction profiles obtained for (a) CP and (b) RCS.

(Roman \& Winter, 2004; Suñol, Miralpeix, Saurina, Carrillo, \& Colom, 2005).

The TG curve obtained for RCS showed different steps and a lower thermal stability compared to the observed for CP (Fig. 3b). One possible explanation for the decreasing thermal stability is the fact that this material has low crystallinity and low degree of polymerization. The high water absorption of RCS corroborates this aspect. TG curves show that the percentage of water released is higher for sample RCS, reaching approximately $15 \%$ weight loss, while for $\mathrm{CP}$ this value reaching about $8 \%$. This difference is associated with the morphology of regenerated cellulose that has a lower degree of crystallinity. The water absorption is favored by the increased of amorphous phase of the RCS sample. Moreover, the high porosity of this sample explains high water absorption.

Two other events can be observed, related to the decomposition of cellulose. The occurrence of two events of decomposition indicates that the material presents a heterogeneous structure, probably a result of the distribution of polymer chains of different lengths. In the second event, there is the degradation of cellulose with mass loss between 150 and $210^{\circ} \mathrm{C}$. Such event is related to water release probably associated with the onset of the degradation of low molecular weight cellulose. Around $215^{\circ} \mathrm{C}$, the mass falls sharply, showing the cellulose degradation followed by the formation of carbon residues (Singh, Arora, \& Lal, 1996).

In fact the regeneration process leads to reduction in the degree of polymerization of cellulose when compared with the CP. Cotton and other cellulosic fibers have a degree of polymerization
(DP) in the range of $800-10000$, depending on the treatment used to extract cellulose. Regenerated cellulose fibers contain 250-500 repeating units per chain (Gemgard, 2007). There is a step in viscose rayon process when the alkali cellulose maturation occurs, followed by cellulose depolymerization in the presence of oxygen. This step has the aim of controlling the polymerization degree. Therefore, it is possible to control the polymerization degree of regenerated cellulose by viscose process. This control is an important factor in the selection of possible applications of the regenerated cellulose materials.

DTG curves show the maximum temperatures for each event of mass loss. RCS sample showed a profile with sequential events completely different from CP. The last one presents one step of thermal degradation $\left(T_{\max } 360^{\circ} \mathrm{C}\right)$ due to the formation of carbon residues. In contrast, RCS sample displays distinct events of decomposition $\left(T_{\max }=180^{\circ} \mathrm{C}, 345^{\circ} \mathrm{C}\right.$ and $\left.380^{\circ} \mathrm{C}\right)$. With this data, we conclude that these events are related to the decomposition of RCS. The decrease in the decomposition temperature of RCS may be related mainly to two aspects: the reduction of the size of the chains due to the viscose process and a decrease in crystallinity, as shown in XRD.

\subsection{In vitro enzymatic degradation}

Fig. 4 shows the behavior of in vitro enzymatic degradation for RCS samples. Hu and Catchmark (2011a, 2011b) showed a satisfactory in vitro biodegradability of bacterial cellulose using specific cellulases, such as $T$. reesei cellulase ( $\operatorname{Tr}$ cellulase). These authors
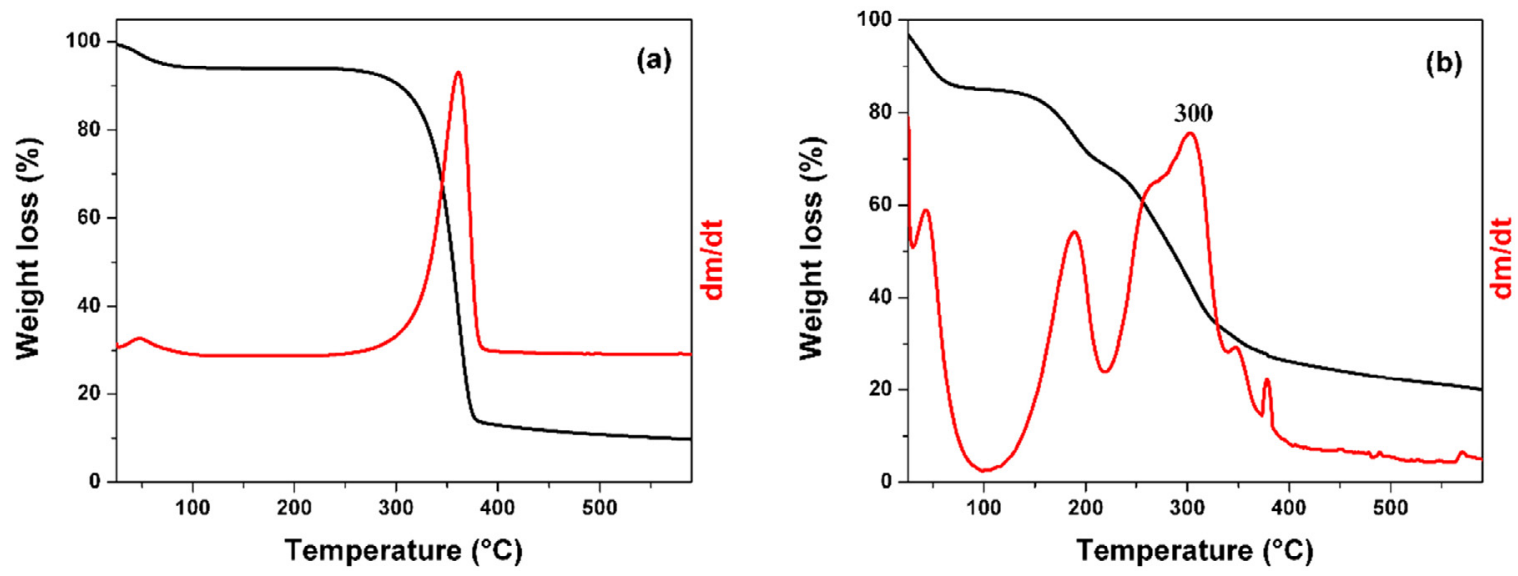

Fig. 3. Thermogravimetric and derivative thermogravimetric curves of $\mathrm{CP}(\mathrm{a})$ and RCS (b). 


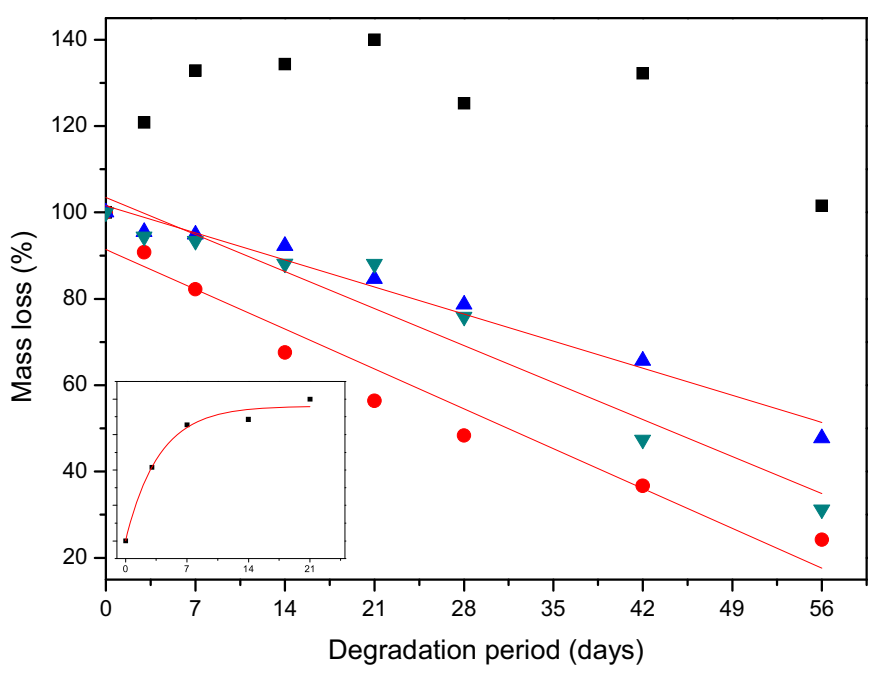

Fig. 4. Enzymatic degradation of RCS: samples treated with lysozyme solution $0.5 \mathrm{U} \mathrm{mL}^{-1}$ (blue triangle) and $1 \mathrm{U} \mathrm{mL}^{-1}$ (green triangle); sample treated with $\mathrm{Tr}$ cellulase solution $0.5 \mathrm{U} \mathrm{mL}^{-1}$ (red circle); standard sample without enzymatic treatment (RCS control; black square). The RCS sample without enzymatic treatment (immersed into SBF solution) gained weight at the first seven days, and reached the equilibrium after 21 days. (For interpretation of the references to color in this figure legend, the reader is referred to the web version of this article.)

evaluated the bacterial cellulose degradation in the period of five days and at day 7 they observed that the samples containing $\mathrm{Tr}$ cellulase showed a weight loss of $50 \%$. In general, the samples containing the $T$. reesei enzyme presented the slowest degradation time regarding the action of other enzymes (Hu \& Catchmark, 2011a, 2011b).

The $\operatorname{Tr}$ cellulase was used in the present experiment and a high degradation activity of RCS was observed. After 28 and 56 days the mass loss was $51.6 \%$ and $75.7 \%$, respectively for the samples containing $0.5 \mathrm{U} \mathrm{mL}^{-1}$ of enzyme per $\mathrm{cm}^{3}$. Samples containing $1.0 \mathrm{U} \mathrm{mL}^{-1}$ of enzyme per $\mathrm{cm}^{3}$ were completely degraded within three days. Therefore the enzymatic concentration must be carefully chosen to achieve a slow and ideal degradation profile, in case these samples may be used as scaffold in tissue engineering.

Lysozyme was chosen for comparison due to its catalytic action in $\beta-1,4$ linkages between $\mathrm{N}$-acetylmuramic acid and N-acetyl-Dglucosamine residues. It is found in tears and mucus of humans as well as in some bacteria and other organisms (Jollbs \& Jollbs, 1984). This enzyme showed a mildest catalytic action when compared to $\operatorname{Tr}$ cellulase. The degradation of the samples containing $0.5 \mathrm{U} \mathrm{mL}^{-1}$ of lysozyme in the periods of 28 and 56 days was $21.3 \%$ and $52.3 \%$, respectively. There was no significant difference between the samples containing lysozyme in the concentrations of $0.5 \mathrm{U} \mathrm{mL}^{-1}$ and $1.0 \mathrm{U} \mathrm{mL}^{-1}$ until the degradation period of 28 days. The degradation profiles observed for samples containing lysozyme were quite satisfactory for application of these materials in tissue engineering as scaffold, since the goal is to create resorbable biomaterials, respecting the time required for obtaining the new tissue formation. SEM images for degraded samples may be found in supplementary material.

\subsection{Cytotoxicity, genotoxicity and mutagenicity assays}

Cytotoxicity results expressed by XTT cell viability assay are presented together with Clonogenic assays (colony formation assays) in supplementary materials for the sake of space. The tested eluates presented high cell viability and they did not present statistically significant difference compared to the NC ( $p>0.05$; Dunnett's test).

Clonogenic assays, or colony formation assays, measure clonogenic potential, i.e., the proliferative ability of single cells to form a colony (Yalkinoglu, Schlehofer, \& zur Hausen, 1990). Besides colony formation, this assay measures cell survival and is routinely used as a sensitive model for assessing long-term cytotoxicity.

The cell surviving fraction results obtained by clonogenic survival assay show that RCS100\%, RCS75\% and RCS50\% exhibit surviving fraction statistically similar to NC $(p>0.05)$. RCS25\% presented a significant increase of the proliferative capacity of the CHO-K1 cells compared to NC $(p<0.05)$.

XTT cell viability assay shows immediate cytotoxic effect on the cells while the clonogenic survival assay shows if other damages may have occurred to cells that stop their proliferative capacity in a later time. By the analysis of the cytotoxicity assays (XTT and clonogenic survival assays), regenerated cellulose scaffolds were not cytotoxic, did not inhibit the proliferative capacity of the CHOK1 cells.

Regarding genotoxicity test, the Comet assay or Single Cell Gel Electrophoresis is capable of detecting DNA double-strand breaks, alkali-labile sites and single-strand breaks associated with incomplete excision repair sites (Tice et al., 2000). The results of the percentage of DNA in tail, Tail Moment, and DDI indicated that none of the eluates presented genotoxicity. In addition, the genotoxic potential presented by regenerated cellulose scaffolds decreased as the dilution of the eluate is increased, neither of them presented a statistically significant difference compared to NC ( $p>0.05$, Dunnett's test). Numeric results are shown in supplementary material.

Observing the results of the regenerated cellulose scaffolds in different assays, it was verified that the RCS eluates did not show cytotoxic, mutagenic and genotoxic potential when in contact with CHO-K1 cells for $24 \mathrm{~h}$.

In literature, studies focusing toxicity of regenerated cellulose are very scarce. Song et al. (2014) investigated cellulose film regenerated from Styela clava tunics (SCT-CF), which were implanted in Sprague-Dawley rats for various lengths of time. The authors did not find differences in the number of white blood cells or metabolic enzymes representing liver and kidney toxicity in the serum of SCT-CF implanted rats in comparison with vehicle implanted rats. Moreover, no significant alteration of the epidermal hyperplasia, inflammatory cell infiltration, redness, and edema were observed in rats implanted with SCT-CF (Song et al., 2014). No in vivo toxicity test was performed in the present study but from the in vitro test it can be said that similar non-toxicity results were observed.

\section{Conclusions}

Regenerated cellulose scaffolds were prepared by viscose process. The samples exhibited structure compatible with the cellulose II, low crystallinity and a lower thermal stability. These requirements are important to ensure biodegradability of the scaffold. RCS also showed a slower in vitro degradation profile for samples containing lysozyme compared to samples containing $\operatorname{Tr}$ cellulase. In addition, RCS did not show cytotoxicity, mutagenic and genotoxic potential. Thus, we can conclude that the regenerated cellulose scaffold is a viable biomaterial with promising features, which allows us to follow up the investigations regarding the development of scaffolds for medical and biological applications. Future in vivo studies will be conducted in order to confirm the potential of regenerated cellulose for such applicability.

\section{Acknowledgements}

The authors thank Brazilian agencies FAPESP, CAPES and CNPq for financial support. In addition, the company Coopercell Ind. de Papel Celofane (São Paulo, Brazil) for supplying the pristine regenerated cellulose and the LMA-IQ for FEG-SEM facilities. 


\section{Appendix A. Supplementary data}

Supplementary data associated with this article can be found, in the online version, at doi:10.1016/j.carbpol.2015.09.066.

\section{References}

Azqueta, A., Meier, S., Priestley, C., Gutzkow, K. B., Brunborg, G., Sallette, J., et al. (2011). The influence of scoring method on variability in results obtained with the comet assay. Mutagenesis, 26, 393-399.

Beguin, P., \& Aubert, J. P. (1994). The biological degradation of cellulose. FEMS Microbiology Reviews, 13, 25-58.

Collins, A. R. (2004). The comet assay for DNA damage and repair: Principles, applications, and limitations. Molecular Biotechnology, 26, 249-261.

Cross, C. F., Bevan, E. J., \& Beadle, C. (1893). Die Chemie der Pflanzenfasern. Cellulosen, Oxycellulosen, Lignocellulosen. Berichte der Deutschen Chemischen Gesellschaft, 26, 2520-2533.

Cross, C. F., Bevan, E. T., \& Beadle, C. (1893). Thiokohlensäureester der cellulose. Berichte der Deutschen Chemischen Gesellschaft, 26, 1090-1097.

Cullen, B., Watt, P. W., Lundqvist, C., Silcock, D., Schmidt, R. J., Bogan, D., et al. (2002). The role of oxidised regenerated cellulose/collagen in chronic wound repair and its potential mechanism of action. The International Journal of Biochemistry \&' Cell Biology, 34, 1544-1556.

Czaja, W., Krystynowicz, A., Bielecki, S., \& Brown, R. M. (2006). Microbial cellulose - The natural power to heal wounds. Biomaterials, 27, 145-151.

Eastmond, D. A., \& Tucker, J. D. (1989). Identification of aneuploidy-inducing agents using cytokinesis-blocked human-lymphocytes and an antikinetochore antibody. Environmental and Molecular Mutagenesis, 13, 34-43.

Fenech, M. (2000). The in vitro micronucleus technique. Mutation Research, 455 $81-95$

Gemgard, U. (2007). From pure cellulose to CMC and viscose - Some process and mechanistic aspect. O Papel, 68, 68-88.

Hench, L. L., \& Polak, J. M. (2002). Third-generation biomedical materials. Science, 295, 1014-1017.

Hu, Y., \& Catchmark, J. M. (2011a). In vitro biodegradability and mechanical properties of bioabsorbable bacterial cellulose incorporating cellulases. Acta Biomaterialia, 7, 2835-2845.

Hu, Y., \& Catchmark, J. M. (2011b). Integration of cellulases into bacterial cellulose: Toward bioabsorbable cellulose composites. Journal of Biomedical Materials Research Part B: Applied Biomaterials, 97, 114-123.

Jollbs, P., \& Jollbs, J. (1984). What's new in lysozyme research? Molecular and Cellular Biochemistry, 63, 165-189.

Karageorgiou, V., \& Kaplan, D. (2005). Porosity of 3D biomaterial scaffolds and osteogenesis. Biomaterials, 26, 5474-5491.

Klemm, D., Heublein, B., Fink, H. P., \& Bohn, A. (2005). Cellulose: Fascinating biopolymer and sustainable raw material. Angewandte Chemie International Edition, 44, 3358-3393.

Kokubo, T., Kushitani, H., Sakka, S., Kitsugi, T., \& Yamamuro, T. (1990). Solutions able to reproduce in vivo surface-structure change in bioactive glass-ceramic
A-W. Journal of Biomedical Materials Research Part A, 24, $721-734$

Liu, S. A., Cheng, C. C., Chen, J. S., Hung, Y. W., Chen, F. J., \& Chiu, Y. T. (2012). Effect of oxidized regenerated cellulose on the healing of pharyngeal wound: An experimental animal study. Journal of the Chinese Medical Association, 75, $176-182$.

Liu, X., \& Ma, P. X. (2004). Polymeric scaffolds for bone tissue engineering. Annals of Biomedical Engineering, 32, 477-486.

Martson, M., Viljanto, J., Hurme, T., \& Saukko, P. (1998). Biocompatibility of cellulose sponge with bone. European Surgical Research, 30, 426-432.

Martson, M., Viljanto, J., Hurme, T., Laippala, P., \& Saukko, P. (1999). Is cellulose sponge degradable or stable as implantation material? An in vivo subcutaneous study in the rat. Biomaterials, 20, 1989-1995.

Rambo, C. R., Recouvreux, D. O. S., Carminatti, C. A., Pitlovanciv, A. K., Antonio, R. V., \& Porto, L. M. (2008). Template assisted synthesis of porous nanofibrous cellulose membranes for tissue engineering. Materials Science \& Engineering C Biomimetic and Supramolecular Systems, 28, 549-554.

Roman, M., \& Winter, W. T. (2004). Effect of sulfate groups from sulfuric acid hydrolysis on the thermal degradation behavior of bacterial cellulose. Biomacromolecules, 5, 1671-1677.

Sannino, A., Demitri, C., \& Madaghiele, M. (2009). Biodegradable cellulose-based hydrogels: Design and applications. Materials, 2, 353-373.

Spector, M. (2008). Basic principles of scaffolds in tissue engineering. In S. E. Lynch, R. E. Marx, M. Nevins, \& L. A. Wisner-Lynch (Eds.), Tissue engineering: Applications in oral and maxillofacial surgery and periodontics (pp. 27-36). Chicago: Quintessence Publishing Co, Inc.

Singh, R., Arora, S., \& Lal, K. (1996). Thermal and spectral studies on cellulose modified with various cresyldichlorothiophosphates. Thermochimica Acta, 289, 9-11.

Singh, N. P., McCoy, M. T., Tice, R. R., \& Schneider, E. L. (1988). A simple technique for quantitation of low levels of DNA damage in individual cells. Experimental Cell Research, 175, 184-191.

Song, S. H., Kim, J. E., Lee, Y. J., Kwak, M. H., Sung, G. Y., Kwon, S. H., et al. (2014). Cellulose film regenerated from Styela clava tunics have biodegradability, toxicity and biocompatibility in the skin of SD rats. Journal of Material Science: Materials in Medicine, 25, 1519-1530.

Suñol, J. J., Miralpeix, D., Saurina, J., Carrillo, F., \& Colom, X. (2005). Thermal behavior of cellulose fibers with enzymatic on $\mathrm{Na}_{2} \mathrm{CO}_{3}$ treatment. Journal of Thermal Analysis and Calorimetry, 80, 117-121.

Teixeira, A. C., Dos Santos, R. A., Poersch, A., Carrara, H. H., de Andrade, J. M., \& Takahashi, C. S. (2009). DNA repair in Etoposide-induced DNA damage in lymphocytes of breast cancer patients and healthy women. International Journal of Clinical and Experimental Medicine, 2, 280-288.

Tice, R. R., Agurell, E., Anderson, D., Burlinson, B., Hartmann, A., Kobayashi, H., et al (2000). Single cell gel/comet assay: Guidelines for in vitro and in vivo genetic toxicology testing. Environmental and Molecular Mutagenesis, 35, 206-221.

Yalkinoglu, A. O., Schlehofer, J. R., \& zur Hausen, H. (1990). Inhibition of $\mathrm{N}$-methyl-N'-nitro-N-nitrosoguanidine-induced methotrexate and adriamycin resistance in $\mathrm{CHO}$ cells by adeno-associated virus type 2. International Journal of Cancer, 45, 1195-1203. 